\title{
A gain-of-function senescence bypass screen identifies the homeobox transcription factor DLX2 as a regulator of ATM-p53 signaling
}

\author{
Yifan Wang, Qikai Xu, Laura Sack, Chanhee Kang, and Stephen J. Elledge \\ Department of Genetics, Harvard University Medical School, Howard Hughes Medical Institute, Division of Genetics, Brigham \\ and Women's Hospital, Boston, Massachusetts 02115 USA
}

Senescence stimuli activate multiple tumor suppressor pathways to initiate cycle arrest and a differentiation program characteristic of senescent cells. We performed a two-stage, gain-of-function screen to select for the genes whose enhanced expression can bypass replicative senescence. We uncovered multiple genes known to be involved in p53 and $\mathrm{Rb}$ regulation and ATM regulation, two components of the CST (CTC1-STN1-TEN1) complex involved in preventing telomere erosion, and genes such as REST and FOXO4 that have been implicated in aging. Among the new genes now implicated in senescence, we identified DLX2, a homeobox transcription factor that has been shown to be required for tumor growth and metastasis and is associated with poor cancer prognosis. Growth analysis showed that DLX2 expression led to increased cellular replicative life span. Our data suggest that DLX2 expression reduces the protein components of the TTI1/TTI2/TEL2 complex, a key complex required for the proper folding and stabilization of ATM and other members of the PIKK (phosphatidylinositol 3-kinase-related kinase) family kinase, leading to reduced ATM-p53 signaling and senescence bypass. We also found that the overexpression of DLX2 exhibited a mutually exclusive relationship with p53 alterations in cancer patients. Our functional screen identified novel players that may promote tumorigenesis by regulating the ATM-p53 pathway and senescence.

[Keywords: ATM; genetic screen; senescence]

Supplemental material is available for this article.

Received September 6, 2015; revised version accepted December 22, 2015.

Cellular senescence was originally described as the irreversible growth arrest that determines the replicative life span in cultured primary cells (Hayflick and Moorhead 1961). Subsequent studies have identified telomere attrition as a primary cause of the replicative senescence program (Bodnar 1998; d'Adda di Fagagna et al. 2003). Cells can sense critically shortened or deprotected telomeres as DNA double-strand breaks (DSBs); thus, they activate the DNA damage response (DDR) network, which relays the signal to tumor suppressor pathways to halt cell cycle progression (Smogorzewska and de Lange 2002; Herbig et al. 2004). Many studies have demonstrated the accumulation of senescence markers during the aging process (Dimri 1995; Herbig et al. 2006). Many senescence regulators, such as p16 and p53, are also known to prevent tumorigenesis (Chen et al. 2005; Collado 2005; Michaloglou et al. 2005). In addition to its tumor suppressor function, senescence has also been implicated in the promotion of tissue repair (Krizhanovsky 2008), development

Corresponding author: selledge@genetics.med.harvard.edu Article is online at http://www.genesdev.org/cgi/doi/10.1101/gad.271445. 115 .
(Munoz-Espin et al. 2013; Storer et al. 2013), and regeneration regulation (Krishnamurthy 2006; Sousa-Victor et al. 2014). While senescence clearly has positive roles as noted above, it also has potentially detrimental roles, as it has been linked to aging itself and age-related inflammation. Recent studies have shown that the systemic ablation of senescent cells alleviates premature aging phenotypes in mouse models (Baker 2011), confirming its part in the promotion of aging and age-related diseases.

In addition to short telomere-triggered replicative senescence, a myriad of other stressors such as tumor suppressor loss, hyperactive oncogenic mutation (Serrano et al. 1997), oxidative stress (von Zglinicki 2002), aneuploidy (Meena et al. 2015), and genotoxic chemical exposure have also been shown to induce senescence, resulting in a variety of cellular alterations. These include strongly elevated secretion of cytokines and chemokines

(C) 2016 Wang et al. This article is distributed exclusively by Cold Spring Harbor Laboratory Press for the first six months after the full-issue publication date (see http://genesdev.cshlp.org/site/misc/terms.xhtml). After six months, it is available under a Creative Commons License (Attribution-NonCommercial 4.0 International), as described at http:// creativecommons.org/licenses/by-nc/4.0/. 
through the senescence-associated secretory phenotype (SASP) pathway (Coppe et al. 2008; Kuilman 2008; Acosta 2013), remodeling of the extracellular matrix (ECM) through secretion of metalloproteases and ECM components (Krizhanovsky 2008), alteration of gene expression networks (Shah 2013), and a globally reshaped epigenetic landscape (Cruickshanks et al. 2013). Despite the fact that a variety of senescence stimuli and consequences exist, a unifying feature of all types of senescence is irreversible cell cycle arrest.

The p53 tumor suppressor pathway plays a pivotal role in the initiation of senescence cell cycle arrest. The DDR network through ATM and ATR activates the p53 tumor suppressor, which in turn engages its downstream transcriptional effectors, including a critical CDK inhibitor, p21, which suppresses inhibitory phosphorylation on RB by several CDK-cyclin complexes to arrest the cell cycle. While, in some cell types, the disruption of the p53-p21 axis is sufficient for bypassing senescence (Herbig et al. 2004), in other cell types (e.g., epithelial cells), additional senescence cell cycle arrest pathways are engaged (Beauséjour et al. 2003). One such pathway is the p16-Rb axis, which is activated by a parallel, less-understood program downstream from ATM and ATR and prevents inhibitory RB phosphorylation by the CDK4/6-Cyclin D complex, establishing another important roadblock to cell cycle progression. Under certain conditions, p15, an INK4 family member related to $\mathrm{p} 16$, can mediate Raf-induced senescence (Kuilman et al. 2008).

Given the complexity of senescence pathways and their many roles in mammalian biology, it is very likely that additional senescence regulators exist that function in known senescence pathways and possibly new pathways. To better understand the senescence regulatory mechanism, we performed a gain-of-function screen to probe for genes that bypass senescence when expressed.

\section{Results \\ Outline for a genome-wide gain-of-function replicative senescence bypass screen}

Multiple tumor suppressor pathways, such as the p53-p21 pathway and the p16-Rb pathway, regulate the human replicative senescence program. Furthermore, we cannot exclude the possibility that additional pathways that affect senescence may exist. Thus, it might be difficult for normal cells to fully bypass senescence with a single genetic alteration. To sensitize our strains, we used cells expressing the HPV E6 or E7 oncoproteins in BJ fibroblasts to selectively attenuate either the p53 or the Rb pathway, respectively. Thus, using these strains, we could screen for regulators of the remaining pathways in a sensitized background. We hypothesized that regulators of the p53 pathway could be selectively uncovered from the E7 BJ cells, and $\mathrm{Rb}$ pathway regulators could be identified from the E6 BJ cells.

We generated a lentiviral library containing $\sim 15,000$ ORFs from the human ORFeome 5.1 library (http:// horfdb.dfci.harvard.edu/hv5) (Rual et al. 2004) and infect- ed mid-aged, proliferating E6 or E7 BJ cells by lentiviral transduction at a low multiplicity of infection (MOI) of 0.5. Cells were puromycin-selected and subsequently passaged for a prolonged period after the majority of the population ceased proliferating due to replicative senescence. In theory, cells containing an individual ORF that bypasses senescence retain their proliferation potential despite the widespread onset of senescence in the screen cell population and thus become relatively enriched in the end sample (Fig. 1A). We quantified the relative enrichment of each ORF in the pooled library with a microarray hybridization protocol. First, we recovered the ORFeome DNA from the start and end sample genomic DNA by PCR amplification. The start and end PCR products were then used for generating Cy3- or Cy5-labeled complementary RNA probes for competitive microarray hybridization that allowed the quantitation of the enrichment score measured by the $\mathrm{Cy} 5 / \mathrm{Cy} 3$ ratio. We used customized microarrays made of multiple oligonucleotide probes for each ORF for quantification and plotted genes based on their average $\log _{2}$ enrichment score and $Z$-score across screen replicates as a measure of senescence bypass phenotype (Fig. 1A).

We tested two customized microarrays made of 25-nucleotide (25-mer) probes or 60-mer probes for each ORF for quantification purposes. While the two platforms produced largely overlapping results, the 25-mer array contained $>10$ probes per gene compared with the 60 -mer array, which contained three probes per gene on average, indicating that it carries higher fidelity with potentially less bias caused by outlier probes due to signal saturation or cross-hybridization. Therefore, we focused on the 25-mer array hybridization data for the primary screen analysis.

\section{Bioinformatic analysis of the primary screen}

We plotted the genes from the E6 and E7 screens based on the $\log _{2}$ enrichment score and $Z$-score (Fig. 1B; Supplemental Tables S1, S2). Surprisingly, we found an outlier annotated as p53 as the strongest hit from the E7 screen. We examined the DNA sequence of the p53 ORF in the ORFeome 5.1 library and found that it contains two point mutations (P72R and P278A) that occur in cancer. We confirmed that the ORF was a dominant-negative mutant, as its expression suppressed $\mathrm{p} 21$ expression (Supplemental Fig. S1). This finding suggested that the E7 screen could successfully identify regulators affecting the p53 pathway in senescence. We noticed that the dominant-negative p53 ORF failed to bypass senescence in the E6 screen despite the strong enrichment in the E7 screen, indicating the selectivity of this sensitized background for identifying p53-independent regulatory genes in E6 BJ cells.

We applied a $Z$-score cutoff of $1.65(P<0.05$, one-tailed test) to select the enriched screen candidates (E7 screen: $\log _{2}$ enrichment of $>1.3, n=433$; E6 screen: $\log _{2}$ enrichment of $>1.19, n=340$ ) (Fig. 1B). To visualize the screen results, we used the Ingenuity Pathway Analysis (IPA) tools to connect scored candidates with known interactions and regulatory relationships according to the Ingenuity knowledgebase of literature. For the E7 screen results, 
DLX2 bypass of senescence by inhibition of ATM

A

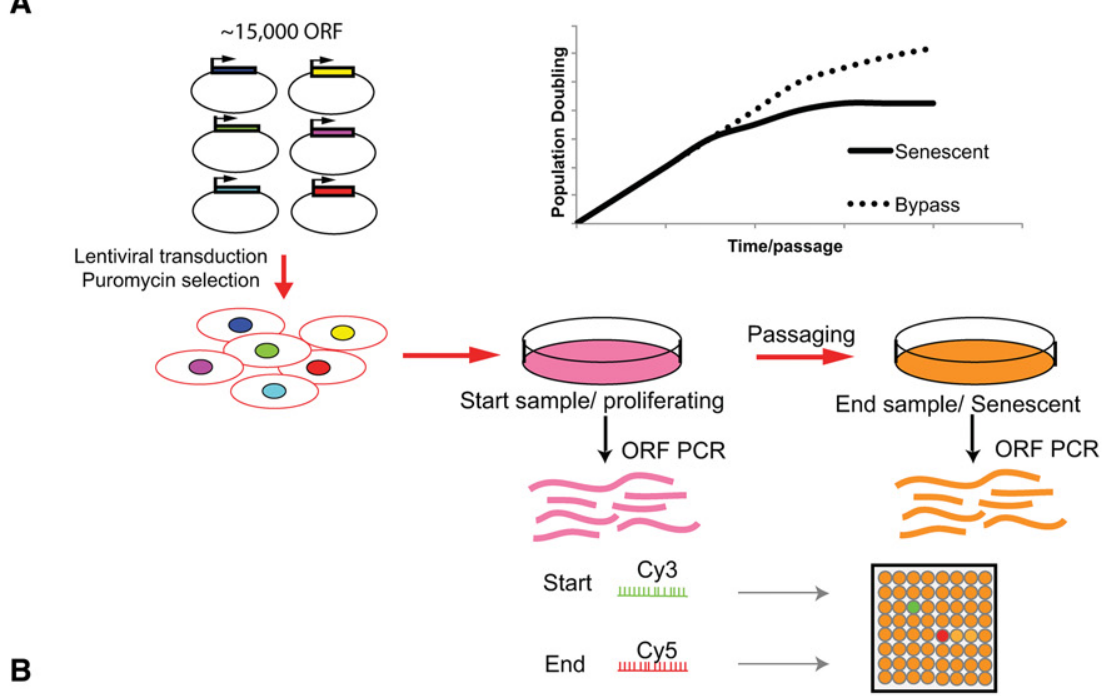

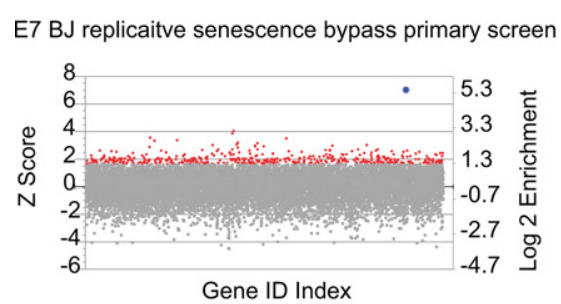

- Z score $>1.65 \cdot$ unscored - mutant p53
E6 BJ replicaitve senescence bypass primary screen

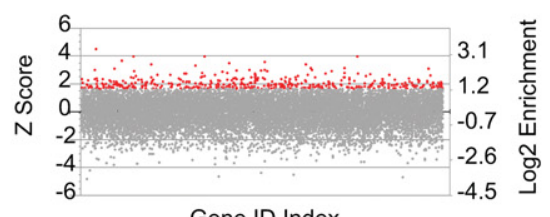

Gene ID Index

- $Z$ score $>1.65$. unscored

C

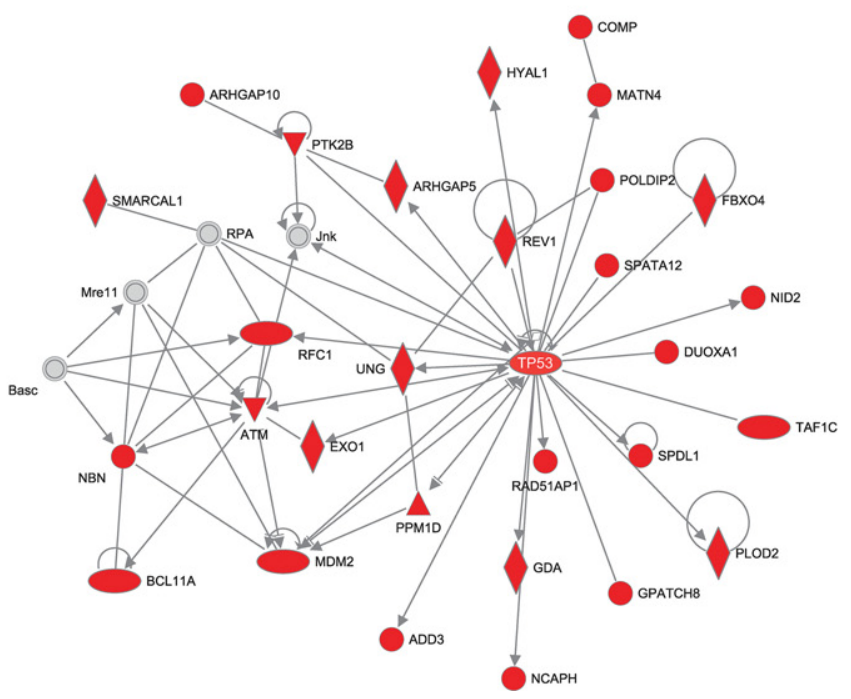

$\triangle$ Phosphatase
$\bigcirc$ Transcription Regulator
$\nabla$ Group/Complex
$\nabla$ Enzyme
$\square$ Relationship
Colors:
$\quad$ Genes scored in screen

Figure 1. Outline of the replicative senescence primary screen. (A) The human ORFeome library 5.1 was introduced to proliferating E6/ E7 BJ fibroblasts by lentiviral transduction at a low MOI of 0.5. Transduced cells were pooled together as the start sample and then passaged after the population became senescent. Cells that bypassed senescence became enriched in the end pool, as indicated by the schematic growth curve. Genomic DNA was extracted from start and end sample for recovering the ORFeome by PCR. Start and end sample PCR products were used to generate differentially labeled cRNA probes for microarray hybridization. (B) E7 and E6 screen results from 25nucleotide (25-mer) array hybridization plotted by $Z$-score (left $Y$-axis) and $\log _{2}$ enrichment score (right $Y$-axis). A mutant p53 ORF was recovered as an outlier from the E7 screen. $(C)$ A network containing multiple p53 functional interacting proteins identified from the genes scored from the E7 screen. Genes shown in red are those scored from the screen. 
one of the top networks derived from the candidates contains multiple p53-interacting proteins (Fig. 1C), including MDM2, PPM1D, and ATM, suggesting the identification of relevant p53 pathway regulators and/or effectors scored from the screen. Note that the ORF that we scored as ATM was actually a truncation of the ATM ORF that is also likely to act in a dominant-negative manner. Along these lines, NBN, which is required for ATM activation and connects ATM to the MRE11-RAD50 complex, also scored. It, too, is likely to act in a dominant-negative manner when overproduced, as it interacts independently with ATM and MRE11-RAD50. We noticed that, besides the well-known p53-interacting proteins mentioned above, this network contained many additional p53-interacting proteins. Since p53 is involved in many aspects of biological process regulation, it would be interesting to explore the additional genes relevant to p53 in the context of senescence. In the top network derived from the E6 screen candidates (Supplemental Fig. S2), we observed E2F2 and several other RB-interacting proteins, including CDK2, Cyclin A, and MDM2. MDM2 is known to promote p53 degradation; however, it has also been shown to promote RB degradation in a p53-independent manner (Sdek et al. 2005; Uchida et al. 2005). Thus, our screen system identified known p53 and $\mathrm{Rb}$ regulators in the senescence screen.

Next, we explored the disease and biological functions related to the screen candidates using the IPA suite of analysis tools. Cancer was the top-scoring disease category in the disease analysis along with several specific cancer subtypes, suggesting that some of the additional novel candidate genes from the screen might represent new cancer drivers (Supplemental Fig. S3A,B; Supplemental Table S3). For the biological function analysis, we identified annotations related to cell proliferation, cell cycle progression, and DNA repair and replication, suggesting that our screen could identify genes with functional relevance to cellular senescence. We also performed a gene ontology (GO) term analysis search based on gene lists ranked by screen enrichment score with the Gorilla tools (http:// cbl-gorilla.cs.technion.ac.il). After applying a false discovery rate (FDR) $q$-value threshold of 0.05 , we identified several significantly enriched GO terms from the E7 screen data set but not the E6 screen data set, including several GO terms related to cellular senescence (Supplemental Fig. S3C; Supplemental Table S4). The genes associated with the senescence GO terms on top of the screen list were TP53, CDK6, ATM, and CTC1. The identification of CTC1 was particularly interesting, since this gene is involved in telomere maintenance, as we discuss below.

\section{Genes scoring in both the E6 and E7 branches}

In principle, in addition to genes that affect either the p53 or $\mathrm{Rb}$ branches, we should be able to identify a third class of genes that affect both branches. For example, we could detect DDR genes that affect sensing of the short telomere signal, genes that reduce telomeric erosion, or genes whose overproduction induce telomerase activity. Another example of a gene that we identified in both branches is the oncogene MDM2. MDM2 is an E3 ubiquitin ligase that is capable of destroying both p53 and RB proteins. We identified a total of 170 genes that scored in both E6 and E7 screens $(Z$-score $>1.65)$ (see Supplemental Fig. S4A; Supplemental Table S5). Several additional genes of this class of genes are described below.

\section{Telomere maintenance: the CST (CTC1-STN1-TEN1) complex}

As telomere shortening initiates replicative senescence, we would expect to identify genes that reduce telomere shortening, enhance its end protection, or enhance telomerase activity itself. One candidate that scored strongly in both the E6 and E7 screens was CTC1. CTC1 encodes a protein component of the CST complex. This complex binds to the $3^{\prime}$ telomeric overhang to promote telomere C-strand fill-in synthesis by DNA polymerase $\alpha$, offsetting telomere attrition caused by exonuclease-mediated end processing independent of telomerase activity $(\mathrm{Wu}$ et al. 2012). If excessive exonuclease resection is not corrected by efficient fill-in resynthesis prior to the next round of DNA replication, then one sister chromosome's telomere will become substantially shorter and could engage the DDR to induce senescence. Stimulating resynthesis reduces the rate of shortening, and, therefore, the CST complex can play a positive role in reducing the telomere attrition rate and avoiding senescence. Interestingly, we found that another component of the CST complex, TEN1 (ORFeome plate ID: 31007@E10), also scored in both the E6 and E7 screens (Supplemental Fig. S4B). The identification of two out of three members of the CST complex indicates that our screening method can identify genes related to telomere maintenance.

\section{Additional factors linked to senescence or aging identified in both screens}

We examined the literature for genes on our list that have previous links to senescence or aging in physiological or pathological contexts. We found several such genes (Supplemental Fig. S4B). REST, a transcriptional repressor that has been suggested to be both a tumor suppressor and an oncogene in different contexts (Negrini et al. 2013), was found in both E6 and E7 screens. Interestingly, a recent study showed that REST displays neuroprotective functions and can ameliorate aging-related neurodegenerative disease (Lu et al. 2014). In addition, RFC1, which encodes a replication factor $C$ subunit involved in DNA replication and repair, was also scored in both the E6 and E7 screens. It has been reported that RFC1 is cleaved and inactivated in the Hutchinson-Gilford progeria syndrome (HGPS) (Tang et al. 2012), and this inactivation might contribute to the replicative cell arrest in HGPS. We also identified FOXO4, a member of the FOXO transcription factor family whose orthologs have been shown to regulate life span and age-related diseases in model organisms (Kenyon 2010; Eijkelenboom and Burgering 2013). Although it is not clear whether FOXO4 can affect age-related physiology in mammals, studies have suggested that FOXO4 is 
involved in protection against oxidative stress at the cellular level (Essers et al. 2004; van der Horst et al. 2006), which may link to cellular aging. Together, our findings strongly suggest that our screen data contain genes with functional relevance to telomere maintenance and other pathways involved in pathological/physiological aging.

\section{Design of a barcode sequencing-based secondary screen}

Due to the high complexity of the ORFeome library and the repeated rounds of cell passaging to allow replicative senescence to occur naturally, we were concerned that the screen might be susceptible to bottlenecking effects and random noise. Furthermore, the microarray-based quantification method has a narrow detection dynamic range determined by the quality and the length of the probe used, and the ORFeome amplification step was prone to PCR bias due to the intrinsic heterogeneous nature of the ORFeome library. We decided to rescreen our primary screen candidates for validation purposes.

In our secondary validation screen, we sought to improve the screening process by developing an array of barcoded lentiviral expression vectors. We generated a collection of 200 gateway destination vectors, each of which contained a cassette containing a unique 25-mer barcode sequence flanked by PCR amplification sequences (Supplemental Fig. S5). We used genes that scored well in the primary screen along with negative control ORFs and individually subcloned them into the barcoded lentiviral vector collection such that each ORF was linked to a defined barcode (Supplemental Fig. S5). We selected genes for constructing one sublibrary for E7 screen hits $\left(\log _{2}>1.75 n=85\right)$ and a second for the E6 screen hits $\left(\log _{2}>1.75 n=67\right)$ with the 25-mer microarray hybridization-derived candidates. The relatively high throughput of the sequencing platform allowed us to include additional genes with a $\log _{2}$ enrichment score above an arbitrary threshold (E7 screen: average $\log _{2}>1.59$ with $\log _{2}>1.95$ in at least two replicates, $n=56$; E6 screen: $\log _{2}>1.45, n$ =91) (Supplemental Table S6) in the sublibraries according to the 60-mer microarray hybridization results. Hence, we constructed one sublibrary with a total of 141 genes to perform a secondary screen on E7-expressing cells and another of 158 genes to perform a secondary screen on E6-expressing cells (Supplemental Table S7). The barcoded sublibraries were introduced into presenescent, proliferating E6 or E7 BJ cells and mixed with cells infected with a pool of 40 barcoded control ORF viruses to repeat the senescence bypass assay. Each ORF's senescence bypass phenotype was monitored using the barcode abundance change determined by sequencing the start and end sample barcodes (Fig. 2A; Supplemental Tables S8, S9).

\section{Improved screen performance in the secondary screen}

Compared with the pool of 40 control ORFs, our candidate genes in the sublibraries achieved significantly higher $\log _{2}$ enrichment scores (Fig. 2B), indicating that our sublibrary content, selected based on the primary screen results, outperformed controls in the assay. Note that we excluded the mutant p53 ORF during the sublibrary construction to avoid potential bottlenecking effects; however, we nevertheless identified multiple strong negative regulators of p53 with robust enrichment scores. For example, the P53 signaling pathway is regulated by a negative feedback loop mediated by the phosphatase PPM1D and the E3 ubiquitin ligase MDM2. In the primary screen, PPM1D and MDM2 both scored modestly. In the secondary screen, we identified PPM1D and MDM2 again with greatly improved enrichment scores (PPM1D $\log _{2}$ enrichment of $>10, Z$-score $=6.4 ;$ MDM2 $\log _{2}$ enrichment of $>8, Z$-score $=5.2$ ) (Fig. 2C). Note that two variants of PPM1D ORFs with different barcodes scored with nearly identical enrichment scores, suggesting a high level of reproducibility. In the E6 sublibrary screen, while both CDK2 and E2F2 were rescored, interestingly, RHOA, a GTPase involved in the p21/p27 and p16/p18/p19 family CDK inhibitor regulatory circuit (Zhang et al. 2009), was identified as one of the highest scoring hits (Fig. 2C). Together, in our secondary screen, the barcoded sequencing platform allowed us to improve the screen performance for selecting genes affecting senescence.

\section{Validation of selected screen candidates}

We noticed that the genes scored from the E7 sublibrary screen exhibited a higher $\log _{2}$ enrichment score than those scored from the E6 screen. We also identified senescence-related GO terms from the E7 branch of the primary screen. We reasoned that this might be due to the fact that the p53 pathway plays a more dominant role in regulating replicative senescence than the $\mathrm{Rb}$ pathway in $\mathrm{BJ}$ cells. Therefore, we decided to focus on the E7 sublibrary hits for further validation. We chose a handful of E7 screen candidate ORFs with varying senescence screen scores to test individually, including a pair of highly related homeobox transcription factors (DLX2 and DLX6), a p53 target gene (TP53I13), a secreted protein (PSG3), a ubiquitin peptidase (UPS15), a transcription factor (MYF6), and a p53-interacting histone demethylase (KDM4D) as well as PPM1D, a p53 phosphatase, as a positive control. We introduced individual ORFs from the ORFeome library to presenescent E7 BJs, repeated the growth curve analysis, and monitored cellular replicative life span. PPM1D, DLX2, DLX6, TP53I13, KDM4D, and USP15 each showed a senescence bypass phenotype when tested individually (Supplemental Fig. S6), while PSG3 and MYF6 failed to validate (Supplemental Fig. S6). Previous reports have suggested that some of the validated genes are involved in the p53 or cell cycle regulation. For example, USP15 was shown to stabilize MDM2 to promote p53 degradation (Zou et al. 2014), which could explain why it scored. We noticed that the TP53I13 and the DLX6 ORFs appeared to be truncated in the ORFeome library when compared with the NCBI reference sequence; therefore, further analysis of full-length ORFs will be required to elucidate the function of these ORFs in senescence. 
A

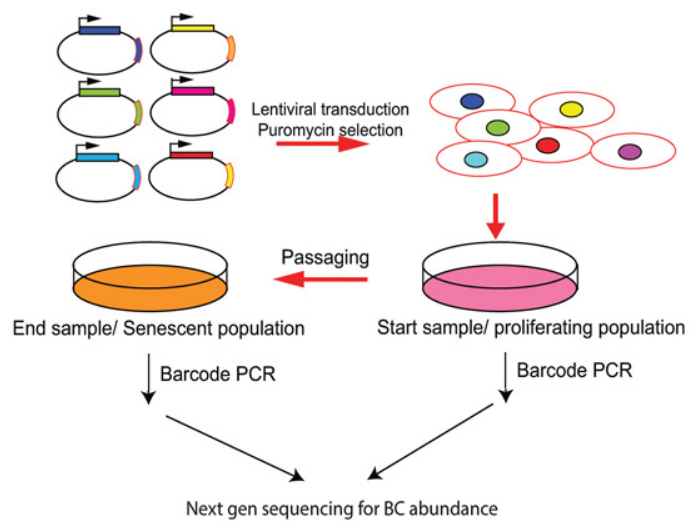

B

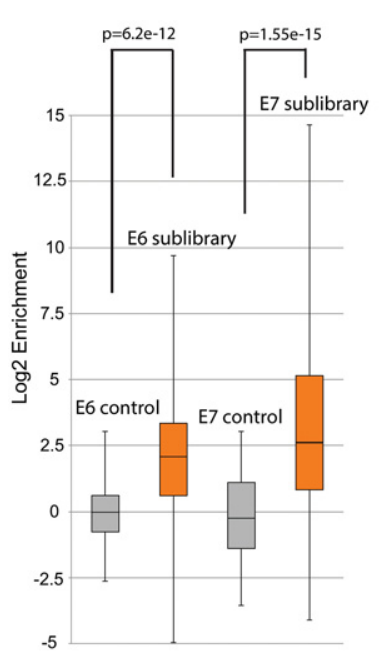

C

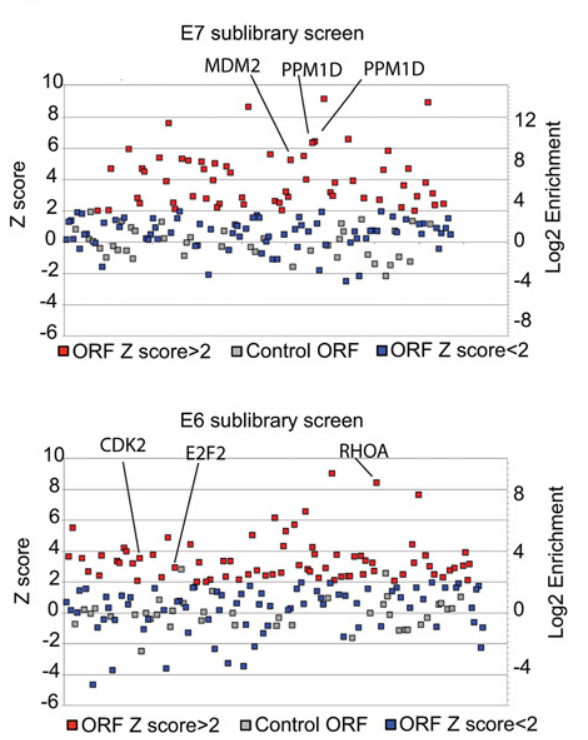

Figure 2. Outline of the secondary senescence sublibrary bypass screen. (A) Candidates picked from the primary screen hits were linked to individual barcodes and introduced to young E6 or E7 cells by lentiviral transduction. Puromycin-selected cells were pooled and passaged after they became senescent. Genomic DNA from the start and end sample was used to amplify the barcodes linked to individual ORFs. The relative abundance of each barcode was determined by next-generation sequencing. $(B)$ Box and whisker plot of $\log _{2}$ enrichment score of 40 control ORFs and the E6 and E7 sublibraries. The E6 and E7 barcoded sublibraries displayed higher $\log _{2}$ enrichment than a pool of 40 control ORFs. The $P$-value was calculated by two-tailed unpaired $t$-test. (C) E7 and E6 sublibrary screen results plotted by $Z$-score (left $Y$-axis) and $\log _{2}$ enrichment score (right $Y$-axis).
Homeobox transcription factor DLX2 identified from the screen

The transcription factor DLX2 belongs to the distal-less homeobox transcription factor family. DLX2 has been reported to be involved in embryonic brain, retina, and craniofacial development (de Melo et al. 2005, 2008; Petryniak et al. 2007; Gordon et al. 2010). In addition to its role in development, high DLX2 expression has been found in a variety of cancers (Yilmaz et al. 2011), and studies have shown that DLX2 expression associates with poor prognosis in glioblastoma and gastric cancer (Tang et al. 2013; Yan et al. 2013). A recent study found that DLX2 is involved in regulating TGF- $\beta$-induced growth arrest, and loss of DLX2 inhibits melanoma tumor growth and metastasis in mouse models (Yilmaz et al. 2011). We found that the full-length DLX2 ORF scored strongly in our primary and secondary senescence screens, and, in our validation assay, we found that DLX2 had a strong phenotype for regulating senescence. Therefore, we decided to investigate the mechanism by which DLX2 expression leads to the bypass of senescence.

We validated the DLX2 senescence bypass phenotype by infecting relatively old, presenescent E7 BJ cells (Sup- plemental Fig. 6B). To test the possibility that DLX2 may increase replicative life span by affecting normal proliferation programs, we introduced DLX2 to mid-aged, nonsenescent cells and monitored proliferation and population doubling (Fig. 3A). We found that DLX2 expression did not alter the growth rate until the cells became aged, before the onset of senescence, suggesting that the senescence bypass phenotype was not due to the cumulative effect of proliferation alteration in a nonsenescent population. We also confirmed the senescence bypass phenotype by staining for senescence-associated $\beta$-galactosidase (SA- $\beta$-Gal) (Fig. 3B,C). In addition, we did not observe significant cell death in control and DLX2-expressing cells during the entire course of the growth curve experiment (data not shown).

\section{DLX2 expression suppresses p53 activation}

Since the p53-p21 pathway plays a pivotal role in senescence regulation in response to DNA damage and since we identified DLX2 together with several other known p53 regulators in the E7 senescence screen, we examined the status of the phosphorylation mark of p53 activation 
A

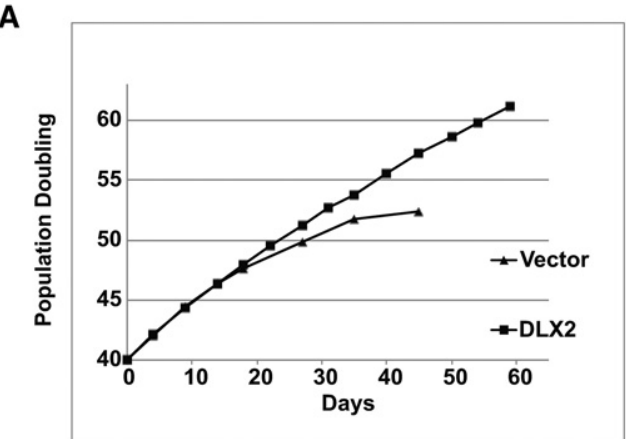

B
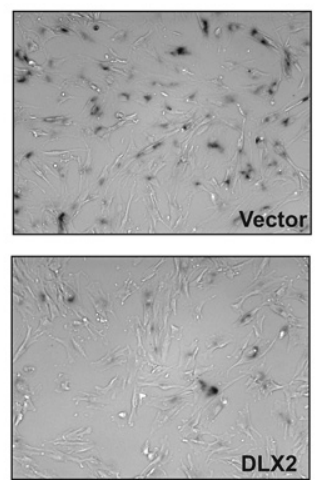

C

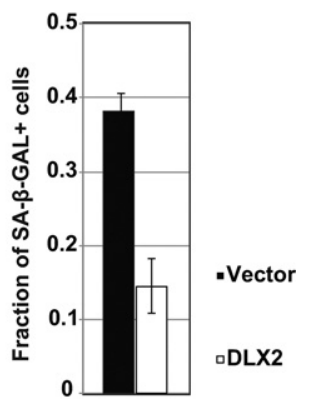

Figure 3. DLX2 expression bypasses replicative senescence. (A) Growth curve of E7 cells infected with DLX2-expressing vector or control vector. $(B)$ Staining for SA- $\beta$-Gal activity in DLX2-expressing and control cells. (C) Quantitation of SA- $\beta$-Gal staining. Error bars represent the standard deviation across three technical replicates.

on Ser15 and $\mathrm{p} 21$ expression level in both young and senescent cells (Fig. 4A,B). We found that DLX2 expression led to reduced $\mathrm{p} 53$ Ser 15 phosphorylation and $\mathrm{p} 21$ expression. As critically shortened telomeres are considered the main source of DNA damage in replicative senescence, we also treated nonsenescent cells with ionizing radiation (IR) to generate DNA DSBs. We found that DLX2 expression also suppresses p53-p21 activation and $\gamma-\mathrm{H} 2 \mathrm{AX}$ formation in IR-treated cells (Fig. 4C,D), suggesting that DLX2 expression may suppress the DDR-p53 pathway in a general manner that is not telomere-specific.

\section{DLX2 suppression of p53 activation requires} the DLL and the homeodomain

DLX2 is a transcription factor that contains a homeodomain at the $\mathrm{C}$ terminus (amino acids 153-211) and a DLL domain in the $\mathrm{N}$ terminus (amino acids 51-132). To determine the domain requirement for DLX2 function, we generated DLX2 mutants with deletions in either the DLL domain $(\Delta 51-132)$ or homeodomain $(\Delta 153-211)$ as well as a mutant ORF that has mutated five arginines and lysines in the homeodomain required for DNA binding (R203A, R204A, K206A, K208A, and K209A) (Fig. 4E). Using a tetracycline (tet)-inducible vector, we con- firmed that both the DLL domain and the homeodomain were required for p53 and DDR suppression by DLX2 induction (Fig. 4E).

DLX2 expression leads to reduced ATM and DNA-PKcs protein levels

Short telomeres and DSBs activate the DDR kinase ATM, which activates p53 transcriptional activity by phosphorylation of p53, MDM2, and CHK2. To further explore the mechanism by which DLX2 expression attenuates p53 and bypasses senescence, we examined the activation of ATM on Ser1981. We found that after $4 \mathrm{~d}$ of doxycycline induction of DLX2 expression, E7-expressing fibroblasts exhibited reduced phosphorylated and total protein levels of ATM. This finding suggests that DLX2 may suppress senescence by its regulation of ATM protein levels (Fig. 5A).

Like ATM, DNA-PKcs also responds to DNA damage by phosphorylating downstream factors, including p53. Therefore, we examined whether DLX2 induction also affected the protein level of DNA-PKcs (Fig. 5B). Interestingly, DLX2 induction profoundly reduced DNA-PK protein level. We quantified the mRNA level of ATM and DNAPKcs by RT-qPCR and found that DLX2 induction did not affect ATM and DNA-PKcs mRNA levels (Fig. 5C), suggesting the involvement of post-transcriptional mechanisms. Both ATM and DNA-PKcs belong to the phosphatidylinositol 3-kinase-related kinase (PIKK) family, which contains four additional members: mTOR, ATR, SMG1, and TRAPP. We examined the mTOR, ATR, and SMG1 protein amounts by Western blotting and found that the other PIKK protein levels were also reduced after DLX2 induction (Fig. 5B,D), indicating that DLX2 affects all PIKK family proteins. In addition, we tested DLX2 mutant induction for ATM and DNA-PK level change and found that the DLL domain and the homeodomain were required for ATM and DNA-PK reduction (Fig. 5E).

\section{DLX2 expression reduces ATM protein levels during senescence}

DLX2 overexpression in proliferating cells resulted in reduced PIKK protein levels. However, we wanted to examine PIKK levels under the physiologically relevant conditions of senescence. Therefore, we asked whether DLX2 expression also reduces PIKK protein levels during the onset of replicative senescence. We found that senescing E7 cells containing vector alone express substantial levels of ATM and mTOR, while age-matched DLX2-expressing cells have markedly reduced levels of ATM and mTOR (Fig. 6A). We also blotted for DNA-PKcs, but DNA-PK levels in replicative senescent cells could not be detected (data not shown). We hypothesized that this might be a characteristic of replicative senescence-mediated differentiation.

Similar to replicative senescence, Ras-induced senescence is also mediated by the DDR. Since DLX2 expression attenuates ATM protein levels and p53 activation, we asked whether DLX2 expression also attenuates Ras- 
A

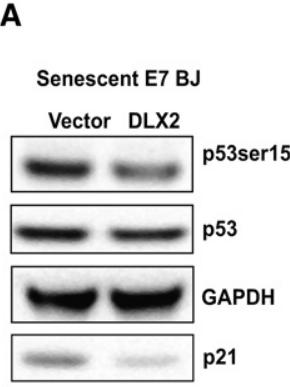

B

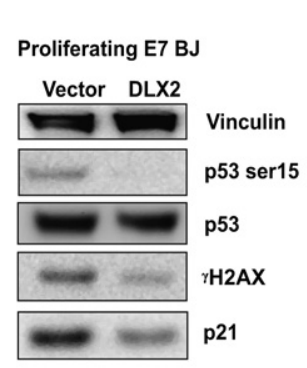

C

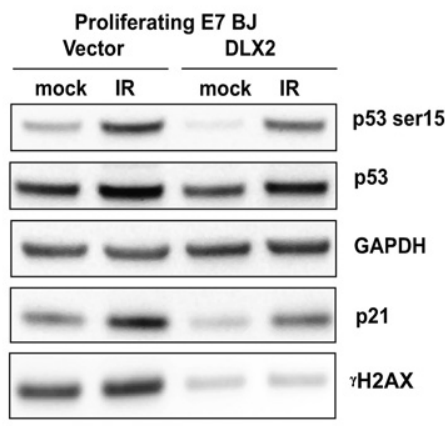

D

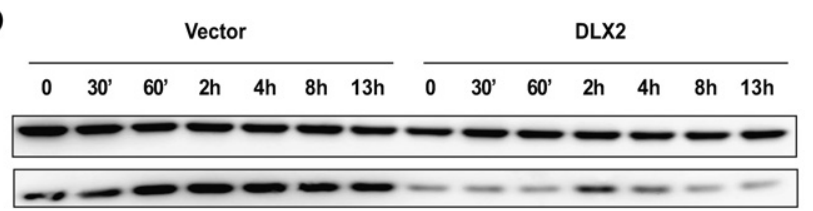

GAPDH rH2AX

E

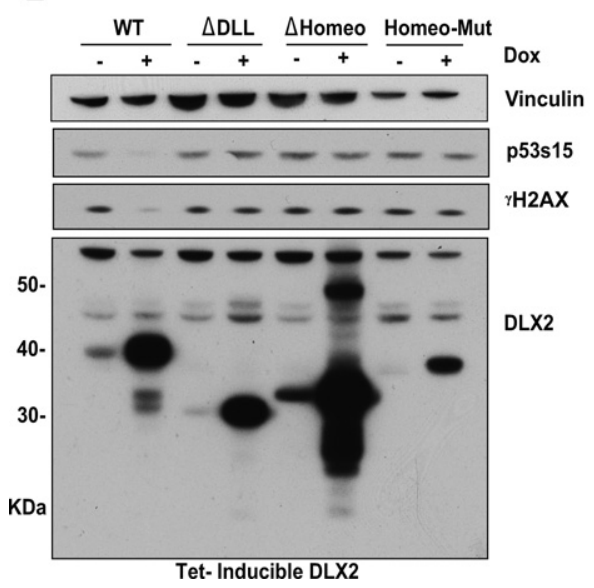

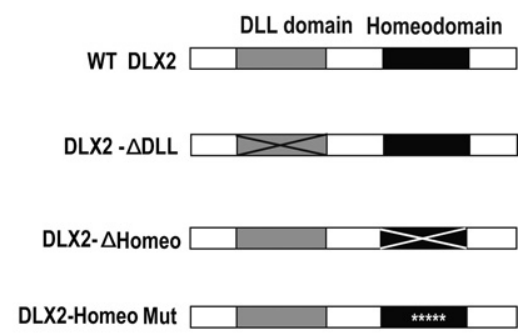

Figure 4. DLX2 expression suppresses p53 activation. (A) DLX2 expression reduced p53 and p21 activation in old (population doubling $[\mathrm{PD}]=52)$ E7 cells. (B) DLX2 expression reduced $\mathrm{p} 53, \mathrm{p} 21$, and $\mathrm{H} 2 \mathrm{AX}$ activation in young, nonsenescent cells $(\mathrm{PD}<45) .(C)$ DLX2 expression reduced p53 and H2AX activation after IR-induced DNA damage. Cells were either treated with 10 Gy of IR or mock-treated and were harvested $24 \mathrm{hr}$ after treatment. Wholecell lysate was used for Western blot. $(D)$ Time-course analysis of $\gamma \mathrm{H} 2 \mathrm{AX}$ levels in cells expressing DLX2 versus control. Cells were treated with $10 \mathrm{~Gy}$ of IR and harvested at the indicated times. (E, left) The DLL and the homeodomain were required for $\mathrm{p} 53$ and $\mathrm{H} 2 \mathrm{AX}$ activation suppression by DLX2 induction. E7 BJ cells containing the tetracycline (tet)-inducible wild-type or mutant DLX2 were treated with $1 \mu \mathrm{g} / \mathrm{mL}$ doxycycline for $4 \mathrm{~d}$ and harvested for Western blot. (Right) Scheme of DLX2 protein domain deletion and point mutation clones. induced senescence. We found that 2 wk after Ras virus infection, hTERT immortalized BJ cells expressing DLX2 showed reduced activation of p53 and the DNA damage marker $\gamma \mathrm{H} 2 \mathrm{AX}$ (Fig. 6B). Consistent with our results with replicative senescence, DLX2 expression also led to reduced levels of ATM and DNA-PKcs protein (Fig. 6C), indicating a conserved mechanism of the DLX2-ATM regulation across senescence caused by different stimuli.

\section{DLX2 expression leads to reduced Triple $T$} (TTI1/TTI2/TEL2) complex component levels

The fact that DLX2 expression affects the levels of multiple PIKK family members prompted us to explore whether DLX2 was involved in a general post-transcriptional regulatory mechanism shared by the whole PIKK family. One such mechanism is PIKK protein stabilization by the Triple T complex (Takai et al. 2007; Hurov et al. 2010). The Triple $\mathrm{T}$ complex contains three components: TEL2, TTI1, and TTI2. This complex interacts with PIKKs and the R2TP complex to recruit the HSP70/90 chaperone machinery for the proper folding and stabilization of the PIKKs (Horejsi et al. 2010). Genetic ablation and siRNA- mediated knockdown of Triple $\mathrm{T}$ genes have been shown to reduce PIKK protein levels (Hurov et al. 2010).

To ascertain whether DLX2 expression impacts the Triple T complex, we examined the protein levels of TEL2 and TTI1 after DLX2 induction by Western blot. We found that DLX2 induction indeed lowered the protein levels of TEL2 and TTI1 (Fig. 7A,B); however, DLX2 expression did not affect TEL2 and TTI1 mRNA levels (Fig. 7C). Since it is known that impaired PIKK kinase folding leads to lysosome-mediated protein degradation (Rao et al. 2014), we tested whether lysosomal protease inhibition would restore ATM and DNA-PKcs protein levels in the presence of DLX2 expression. We observed that leupeptin, a lysosomal protease inhibitor, restored ATM and DNA-PK levels after DLX2 induction, indicating that DLX2 expression results in impaired protein folding and degradation of PIKKs mediated by the Triple T complex (Fig. 7D).

\section{DLX2 overexpression and p53 alteration exhibit a mutually exclusive pattern}

Because DLX2 is mostly expressed during embryonic development, and its expression was undetectable in the 

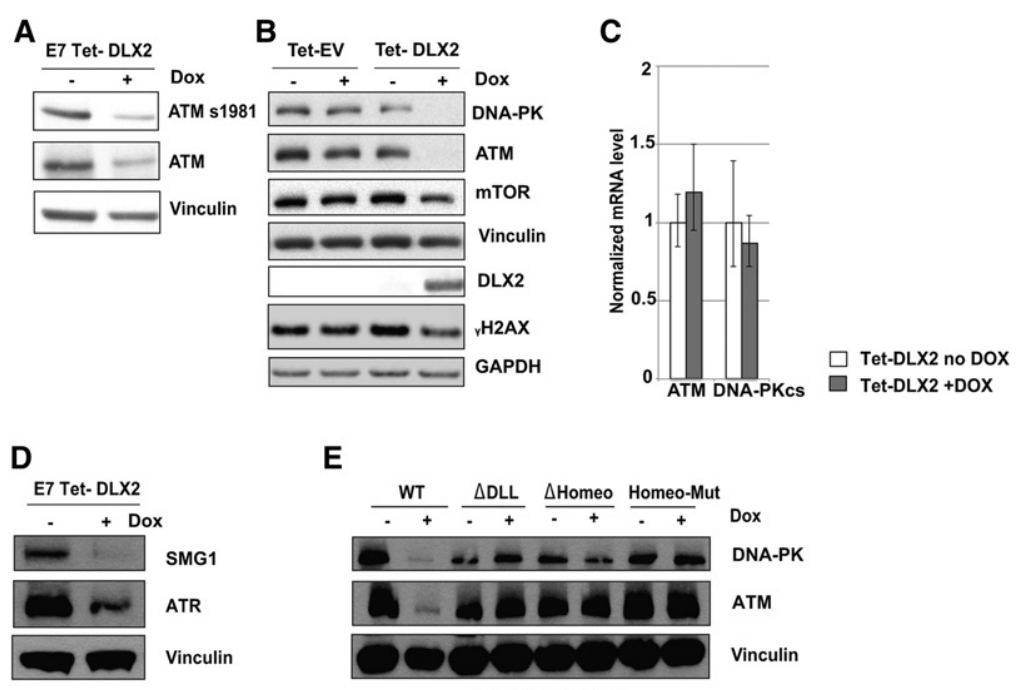

E

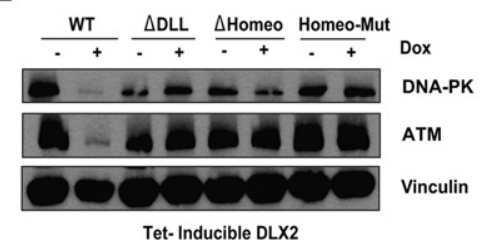

young and senescent diploid fibroblast cells that we used (data not shown), it is unclear whether DLX2 is involved in senescence in normal fibroblasts. On the other hand, cancer cells need to evade the senescence barrier, often by inactivating key senescence pathways such as the p53 pathway. According to our data, DLX2 expression reduces the Triple $\mathrm{T}$ complex proteins, leading to the reduced protein amount of ATM and the suppression of the ATM-p53 signaling. Given these findings, we examined the relationship between DLX2 overexpression and p53 alterations (mutation, copy number variation, and mRNA level change) observed in cancer patients with the cBioPortal tool (Cerami et al. 2012; Gao et al. 2013). We searched for large-scale data sets with accessible DNA and RNA sequencing data. In a recently published study of breast cancer patients (Ciriello et al. 2015), DLX2 was overexpressed in a modest fraction of patients (32 out of $971,3 \%$ ), while p53 alterations occurred in 369 out of $971(39 \%)$ patients. Interestingly, we found that cases with DLX2 overexpression exhibited a mutually exclusive pattern with p53 alterations $(P=0.0048)$ (Fig. 7E,F), suggesting that overexpressed DLX2 may negate the need for p53 mutations in cancer cells.

\section{Discussion}

In this study, we describe a genome-wide gain-of-function screen for replicative senescence bypass performed in a sensitized cellular background.
Figure 5. DLX2 expression reduces ATM, DNAPKcs, and mTOR protein levels. (A) DLX2 induction reduced phosphorylated ATM (Ser1981) and total ATM protein levels. (B) DLX2 induction reduced ATM, DNA-PKcs, and mTOR protein levels. $(C)$ DLX2 induction did not alter mRNA levels of ATM and DNA-PKcs. Error bars represent the standard deviation across three technical replicates. $(D)$ E7 BJ tet-DLX2 induction reduced SMG1 and ATR protein levels. (E) E7 BJ cells with tet-inducible wild-type and mutant DLX2 were treated with doxycycline for induction and harvested for ATM and DNA-PK Western blot. E7 BJ cells containing the tet-inducible DLX2 vector were treated with $1 \mu \mathrm{g} / \mathrm{mL}$ doxycycline for $4 \mathrm{~d}$
In the primary E7 screen, we uncovered a dominantnegative p53 ORF. Our network analysis revealed that many known regulators of the p53 and RB pathways were identified from the top networks derived from the E7 and the E6 screen candidate lists. These findings suggest that we can find relevant genes from our screen and justify the use of a sensitized genetic background for senescence screens. In our analysis of genes scored in both E6 and E7 screens, we identified the CST complex component genes CTC1 and TEN1, suggesting that our screen successfully identified factors involving the telomere maintenance machinery and that additional telomere maintenance proteins might also be among the other candidates on our list. In addition, we uncovered a group of genes related to aging pathology or physiology, including REST, RFC1, and FOXO4, indicating that our screen may identify additional senescence regulators with a broad physiological impact.

Our primary screen efforts appeared to have identified multiple genes relevant to senescence. However, due to the multiple rounds of cell passaging and the large size of the ORFeome library, we reasoned that the screen accuracy may be undermined by potential bottlenecking effects and noise accumulation. Despite this, we were able to derive gene networks with candidates known to interact with p53 or $\mathrm{Rb}$, which gave us confidence in the quality of the screen that we feel will provide a contextual basis for constructing future hypotheses for interested readers.
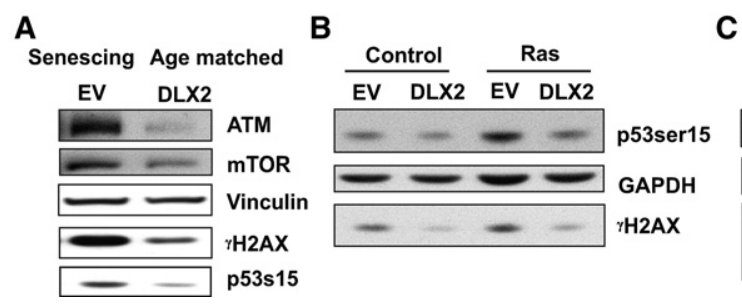

C

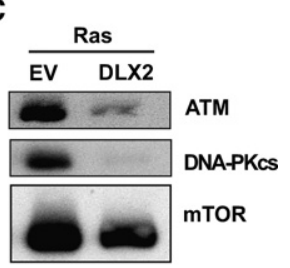

Figure 6. DLX2 expression reduced PIKKs during senescence. (A) E7 BJ cells constitutively expressing DLX2 exhibited reduced levels of ATM and mTOR compared with senescent empty vector (EV) control cells. $(B, C)$ DLX2 expression reduced p53 and H2AX phosphorylation in Ras-induced senescence in hTERT immortalized BJ cells. DLX2 expression led to reduced levels of ATM, DNA-PK, and mTOR compared with control cells. Cells were infected with retroviral $\mathrm{H}-\mathrm{RasV} 12$ virus and harvested $14 \mathrm{~d}$ after infection. 
A

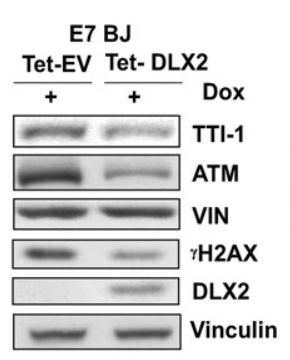

c

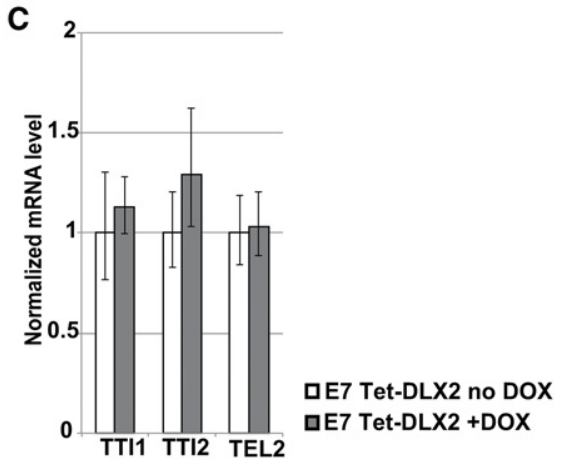

E

\begin{tabular}{|l|c|c|}
\hline & p53 alteration & p53 normal \\
\hline DLX2 over-expression & 5 & 27 \\
\hline DLX2 normal & 364 & 575 \\
\hline total patient $\mathrm{N}=971$ & $\mathrm{P}$ value $=0.0048$
\end{tabular}

$\mathbf{F}$

p53

DLX2

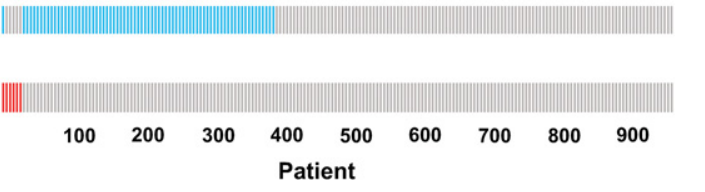

| p53 altered || p53 normal

| DLX2 OE | DLX2 normal
Figure 7. DLX2 expression leads to reduced Triple $\mathrm{T}$ complex component levels. (A) DLX2 induction led to reduced TTI1 protein level in E7 BJ and IMR90 cells. $(B)$ DLX2 induction led to reduced TEL2 protein levels in IMR90 cells. (C) DLX2 induction did not alter the mRNA level of TTI1, TTI2, and TEL2. (D) Leupeptin treatment restored DLX2-induced ATM protein reduction. E7 BJ cells with inducible DLX2 were induced with $1 \mu \mathrm{g} / \mathrm{mL}$ doxycycline for $5 \mathrm{~d}$ and then treated with DMSO or $100 \mu \mathrm{M}$ leupeptin $24 \mathrm{hr}$ prior to harvesting. (E) Statistics of DLX2-p53 mutual exclusivity. The $P$-value was calculated by Fisher's exact test. $(F)$ Visual overview of patients with DLX2 overexpression and p53 alteration. Data from all 971 patients are plotted horizontally on the $X$-axis, with each bar representing five patients. (Top row) p53 alteration status. (Blue) Cases with p53 alteration; (gray) normal p53. (Bottom row) DLX2 overexpression status. (Red) Cases with DLX2 overexpression; (gray) normal DLX2 expression levels. Data were acquired from the cBioPortal Web tool (http://www.cbioportal.org).
To further improve our screen quality, we performed another round of validation screens with an improved assay for quantitation. We reconstructed sublibraries consisting of candidates with DNA barcodes and rescreened them with a next-generation sequencing-based quantification method. This barcode sequencing method has significant advantages over the microarray method of the primary screen: (1) The sequencing method can achieve a higher detection dynamic range than the microarray approach, (2) the probe quality and cross-hybridization issues associated with microarray are eliminated, and $(3)$ the inherent PCR bias associated with ORFeome amplification is minimized by the use of DNA barcodes. Furthermore, the barcoded sublibraries contain many fewer ORFs than the original genome-wide library, and this reduced pool size improved the resolution of the secondary screen assay.

Indeed, we found that the secondary library screens uncovered candidates with high enrichment scores related to existing senescence pathways. In the E7 sublibrary screen, known p53 regulators showed improved ranking compared with the primary screen results. For example, MDM2 and PPM1D were among the top 15 candidates.
USP15, another validated top candidate, has also been shown to affect p53 levels via MDM2 stabilization (Zou et al. 2014). In the E6 sublibrary screen, we identified RHOA, a Rho GTPase protein at the top of the scored gene list that is involved in negatively regulating multiple INK4 family genes, including $16^{\mathrm{INK} 4 \mathrm{a}}, \mathrm{p} 18^{\mathrm{INK} 4 \mathrm{c}}$, and p19 ${ }^{\text {INK4d }}$, in cancer cells. We noticed that the E6 screen candidates generally displayed less striking $Z$-scores compared with the E7 screen candidates in the sublibrary screen. We reasoned that this might be due to the fact that the p53 pathway plays a more prevalent role than the $\mathrm{Rb}$ pathway in $\mathrm{BJ}$ cell replicative senescence. Therefore, we chose to primarily focus on the E7 screen hits for validation purposes.

Among the seven genes that we chose to validate, five genes (DLX2, DLX6, USP15, KDM4D, and TP53I13) exhibited a life span extension phenotype along with PPM1D, corresponding to an approximate validation rate of $70 \%$. PSG3 and MYF6 did not validate when tested individually. We reasoned that virus integration sites or double virus integration could contribute to the occurrence of a small fraction of false positives in the screen 
data. Alternatively, it is possible that they may only enrich when cells were mixed with other nonexpressing populations in a competition situation.

From this screen, we discovered that the expression of homeobox transcription factor DLX2 exhibited a strong effect in extending replicative life span. DLX2 is involved in the negative regulation of the TGF- $\beta$ pathway, and depletion of DLX2 expression leads to inhibition of melanoma tumor growth and metastasis in mouse models (Yilmaz et al. 2011). In our experimental context, we found that DLX2 did not appear to regulate the TGF- $\beta$ pathway (data not shown) in BJ fibroblast cells but instead attenuated the ATM-p53-p21 axis in both proliferating and senescent cells. We observed that DLX2 expression reduced ATM protein levels, and further analysis revealed that DLX2 expression led to reduced protein levels of Triple $\mathrm{T}$ complex components, which are required for the proper folding and stabilization of PIKK family members, including ATM, ATR, DNA-PK, mTOR, SMG1, and TRRAP (Hurov et al. 2010). Our findings suggest a model in which DLX2 expression destabilizes critical DDR kinases ATM and/or DNA-PK via reduction of Triple T complex components and results in suppressed 553 pathway activation. Consequently, the expression of DLX2 allows cells to continue to proliferate in the presence of senescence stimuli such as critically shortened telomeres or DNA lesions associated with oncogenic Ras mutant expression.

Because DLX2 is only transiently expressed during embryonic development and because its expression was absent in the fibroblast cell lines that we tested, it is unclear whether DLX2 participates in the regulation of normal senescence. However, DLX2 expression correlates with tumor progression, metastasis, and poor prognosis in a variety of human cancers, including melanoma, lung cancer, breast cancer, prostate cancer, glioblastoma, and gastric adenocarcinoma. It is possible that DLX2-mediated suppression of the Triple T-ATM-p53 regulatory mechanism is involved in cancer progression in the context of senescence and/or apoptosis regulation. Accordingly, we found that, in a recently published breast cancer patient sequencing study (Ciriello et al. 2015), DLX2 is overexpressed in a small subset of patients $13 \%, 32$ of 971 cases). Its overexpression pattern is mutually exclusive with p53 alterations $(P=0.0048)$, suggesting DLX2 overexpression may negate the $\mathrm{p} 53$ pathway in the absence of $\mathrm{p} 53$ alterations. Future efforts with mouse models and DLX2 loss-of-function studies will be needed to further test this possibility.

The two sensitized screens that we performed identified a large number of new candidate senescence genes that will serve as a resource for future analyses. The identification of so many genes implicated in the ATM, p53, RB, and telomere pathways suggests not only that the screens worked well but that many of the other candidates will likely be impacting these same pathways. The genes that scored in both arms are particularly interesting, as they may give us clues to how senescence is initiated and how telomere attritiion and telomerase are regulated. This gene set will significantly impact our understanding of senescence in the future.

\section{Materials and methods}

Cell culture and general procedures

Human diploid BJ fibroblasts and IMR90 fibroblasts were obtained from American Type Culture Collection and were maintained in $3 \% \mathrm{O}_{2}$ conditions. Cells were grown in DMEMglutamax (Invigtrogen) with 15\% FBS, penicillin-strepomycin, and $0.1 \mathrm{mM}$ nonessential amino acids (Invitrogen). E6/E7-expressing BJs were generated by infecting with retrovirus derived from MSCV-E6 and MSCV-E7 vectors, which were gifts from the deLange laboratory. Retrovirues and lentiviruses were packaged in $293 \mathrm{~T}$ cells transfected with gene expression vectors of interest together with helper plasmids (for retrovirus, VSVg and $\mathrm{Gag} / \mathrm{pol}$; for lentivirus, VSVg, Gag/pol, TAT, and Rev) (Luo et al. 2009). Viral infections were carried out in the presence of $4 \mu \mathrm{g} / \mathrm{mL}$ hexadimethrine bromide.

\section{Growth curve and SA- $\beta$-Gal assays}

Cells were plated at a density between $1 \times 10^{6}$ and $1.5 \times 10^{6}$ per 10 -cm tissue culture plate $\left(127 \times 10^{3}\right.$ to $191 \times 10^{3}$ per square centimeter) and fed every 2-3 d. Cells number was monitored using a Coulter counter for calculating population doublings. Cells were continuously passaged until the growth curve became flat. The SA- $\beta$-Gal assay was performed using a senescent cell staining kit (Sigma) following the manufacturer's instructions.

\section{Plasmids and cloning}

pWZL-hygro-HRasV12 and pWZL-hygro control vectors for the Ras-induced senescence experiments were obtained from Addgene. pHAGE-TREx lentiviral vector was used for constitutive DLX2 expression in E7 BJ and IMR90 cells, and this vector was previously described (Yoon et al. 2014). A pHAGE-CMV-N-FlagHA lentiviral vector was used for DLX2 expression in hTERT immortalized BJ cells.

The DLX2 mutant ORFs used for domain analysis were generated by overlap extension PCR and subsequently cloned into a pDONR-223 vector with BP cloning followed by LR reaction into pHAGE-Inducer-20 (Meerbrey et al. 2011).

\section{Immunoblotting and antibodies}

Cells were lysed in $1 \times$ NuPAGE LDS sample buffer supplemented with $1 \times$ Bond-Breaker TCEP (Life Technologies) and $1 \times$ Halt protease and phosphatase cocktail (Life Technologies) on ice. The whole-cell lysates were sonicated briefly to break down the chromatin. Samples were boiled for $5 \mathrm{~min}$ at $95^{\circ} \mathrm{C}$ and then loaded to $4 \%-12 \%$ Bris-Tris SDS protein gel or $3 \%-8 \%$ Tris acetate SDS protein gel (Life Technologies).

The antibodies used were as follows: p53 (Calbiochem, DO-1), phospho-p53s15 (Cell Signaling, 9284), p21 (Calbiochem, OP64), DLX2 (Abcam, ab30339), $\gamma \mathrm{H} 2 \mathrm{AX}$ (Millipore, 05-636), vinculin (Sigma, V9131), phospho-ATMs1981 (Abcam, ab81292), ATM (Genetex, GTX70103), DNA-PKcs (Bethyl Laboratories, A300517A), mTOR (Cell Signaling, 4517), ATR (Bethyl Laboratories, A300-137A), SMG1 (Bethyl Laboratories, A300-394A), TTI1 (Bethyl Laboratories, A303-451A), and TEL2 (ProteinTech, 15975-1-AP).

$R T-q P C R$

Total RNA was isolated using the RNAeasy minikit (Qiagen), and cDNA was synthesized using a SuperScript VILO cDNA 
synthesis kit (Invitrogen) according to the manufacturer's instructions. Quantitative RT-PCR was performed in triplicate or quadruplicate using the TaqMan gene expression master mix (Invitrogen) with TaqMan gene expression assay (Life Technologies) on an Applied Biosystems Fast 7500 machine using GAPDH as the endogenous normalization control, and data were normalized to empty vector control cells. The IDs for the TaqMan assays used were as follows: ATM (Hs01112314_m1), DNA-PKcs (Hs04195439_s1), TTI1 (Hs00384863_m1), TTI2 (Hs002283 57_m1), TEL2 (Hs0021 1542_m1), GAPDH (Hs02758991_g1), and p21 (Hs99999142_m1).

\section{ORFeome-based senescence bypass primary screen}

The general workflow of the senescence primary screen is described in Figure 1. Approximately $8 \times 10^{6}$ infected cells were cultured in three replicates, with a representation of 500 copies per ORF in the library. The start and end sample cells were harvested with $>1 \times 10^{7}$ cells per pellet. Pellets were lysed in $10 \mathrm{mM}$ Tris $(\mathrm{pH} 8.0), 10 \mathrm{mM}$ EDTA, $0.5 \%$ SDS, and $0.2 \mathrm{mg} / \mathrm{mL}$ Proteinase $\mathrm{K}$ overnight at $55^{\circ} \mathrm{C}$. Genomic DNA was extracted with phaselock tubes with phenol:chloroform and chloroform. The sample was then digested with $25 \mathrm{\mu g} / \mathrm{mL}$ RNase A for overnight incubation at $37^{\circ} \mathrm{C}$ and extracted with phaselock tubes again as described above. DNA was precipitated with ethanol and washed with $75 \%$ ethanol three times before being resuspended in $\mathrm{H}_{2} \mathrm{O}$. The DNA was PCR-amplified with Takara hot start Taq polymerase (RR006B) with primers flanking the ORF expression cassette (primer 1, 5'-GATCCCTACCGGTGATATCC-3'; primer 2, 5' -TAATACGACTCACTATAGGGAGAGGCCCTCTAGT CGACCTAGC- $3^{\prime}$ ). Purified PCR products were used to generate cRNA probes with a T7 RNA polymerase kit (MEGAscript, Ambion). After purification with Ambion Megaclear kits, the cRNA was further labeled with a ULS labeling kit (Kreatech: start sample cy3; end sample, cy5). Differentially labeled cRNA was hybridized to customized 25-mer or 60-mer microarray chips from Agilent. The microarrays were read with an Agilent scanner.

Primary screen data analysis and candidate selection for sublibrary screens

We processed the probes by filtering out the low-intensity probes, and an individual gene enrichment score was calculated based on the average cy5/cy3 signal ratio across multiple probes of the same gene and normalized to the population median enrichment score. The 60 -mer array contained many low-intensity probes; therefore, after filtering, this platform provided only $~ 60 \%$ coverage compared with the 25 -mer array data. We ranked genes based on average $\log _{2}$ enrichment score across three biological replicates and used the genes scored from the 25-mer microarray with an arbitrary cutoff $Z$-score of $>1.65$ for Ingenuity pathway network analysis.

For E7 sublibrary construction, we selected candidates with an average $\log _{2}$ enrichment of $>1.75$ across all three replicates according to the $25-\mathrm{mer}$ array data and additional complementary genes from the 60-mer array data based on the following criteria: (1) average $\log _{2}$ enrichment of $>1.59$ and (2) scored with $\log _{2}$ enrichment of $>1.95$ in at least two out of three screen replicates. For E6 sublibrary construction, we selected candidates with an average $\log _{2}$ enrichment of $>1.75$ from the 25-mer array data and additional genes with an average $\log _{2}$ enrichment of $>1.45$ according to the 60-mer array data. We picked 40 unscored ORFs from one ORFeome plate (31045) as control ORFs for the sublibrary screen.

\section{Construction of the barcoded sublibrary}

A synthetic 2 X2 5-mer barcode pool from IDT was PCR-amplified with universal primer containing homology with the pHAGE-TREX vector (primer 1, 5'-AGAGATCCAGTTTGGAC TAGGCTAGCCGGTGTCGGTCTCGTAGTT-3'; primer 2, $5^{\prime}$-AGTTATGTAACGACATGCATGCTAGCGTCGTCCAGCTG CGAACGA-3'). The PCR products were gel-purified and mixed with NheI linearized pHAGE-TREX vector following the SLIC (sequence- and ligation-independent cloning) cloning protocol (Li and Elledge 2007). The cloning reaction mix was incubated for $30 \mathrm{~min}$ at $37^{\circ} \mathrm{C}$ and transformed into ccdB-resistant Escherichia coli. Single colonies were picked after transformation, and the plasmid DNA was used for determining the exact barcode sequence by Sanger sequencing. Next, 200 barcoded pHAGE-TREX destination vectors with available barcode information were arrayed on 96-well plates.

LR reaction was carried out in a 96-well plate with individual ORF entry clones and barcoded pHAGE-TREX destination vectors, and the individual LR reaction products were used to transform competent $E$. coli cells in 96-well plates. After transformation, the E. coli from 200 wells were pooled together to prepare the sublibrary DNA for virus packing purpose.

\section{Barcoded sublibrary screen}

The workflow of the barcoded sublibrary screen is described in Figure 2. Specifically, $1 \times 10^{6}$ cells were infected with the E6 or E7 barcoded sublibrary with low MOI. The same number of cells was infected with the barcoded control ORF pool and mixed with the sublibrary cells to form the start cell population. The cells were passaged after reaching senescence, and both start and end cells were harvested for extracting genomic DNA. The genomic DNA was PCR-amplified with the following primers: primer 1 (5'-CGCCGAATTCACAAATGGCAGT-3') and primer 2 (5'-GGA CATCCGAGCTCGATATCATCG-3'). The PCR products were subsequently amplified with indexing primers, pooled together, and sequenced with a customized sequencing primer $\left(5^{\prime}\right.$-CTAG GCTAGCCGGTGTCGGTCTCGTAGTT-3'). Each gene's enrichment score was calculated using the relative barcode abundance in the start and end sample and normalized to the average control ORF enrichment score.

\section{Acknowledgments}

We thank members of the Elledge laboratory, A. Burrows, A. Smogorzewska, M. Li, and T. de Lange for helpful discussions. We also thank T. de Lange for the E6 and E7 viruses, and A. Smogorzewska for the E6 and E7 BJ cells. This work was supported by National Institutes of Health grant GM44644 to S.J.E. S. J.E. is an Investigator with the Howard Hughes Medical Institute.

\section{References}

Acosta JC. 2013. A complex secretory program orchestrated by the inflammasome controls paracrine senescence. Nat Cell Biol 15: 978-990.

Baker DJ. 2011. Clearance of p16Ink4a-positive senescent cells delays ageing-associated disorders. Nature 479: 232-236.

Beauséjour CM, Krtolica A, Galimi F, Narita M, Lowe SW, Yaswen P, Campisi J. 2003. Reversal of human cellular senescence: roles of the p53 and p16 pathways. EMBO J 22: 4212-4222. 
Bodnar AG. 1998. Extension of life-span by introduction of telomerase into normal human cells. Science 279: 349-352.

Cerami E, Gao J, Dogrusoz U, Gross BE, Sumer SO, Aksoy BA, Jacobsen A, Byrne CJ, Heuer ML, Larsson E, et al. 2012. The cBio cancer genomics portal: an open platform for exploring multidimensional cancer genomics data. Cancer Discov 2: 401-404.

Chen Z, Trotman LC, Shaffer D, Lin HK, Dotan ZA, Niki M, Koutcher JA, Scher HI, Ludwig T, Gerald W, et al. 2005. Crucial role of p53-dependent cellular senescence in suppression of Pten-deficient tumorigenesis. Nature 436: 725-730.

Ciriello G, Gatza ML, Beck AH, Wilkerson MD, Rhie SK, Pastore A, Zhang H, McLellan M, Yau C, Kandoth C, et al. 2015. Comprehensive molecular portraits of invasive lobular breast cancer. Cell 163: 506-519.

Collado M. 2005. Identification of senescent cells in premalignant tumours. Nature 436: 642.

Coppe JP, Patil CK, Rodier F, Sun Y, Munoz DP, Goldstein J, Nelson PS, Desprez PY, Campisi J. 2008. Senescence-associated secretory phenotypes reveal cell-nonautonomous functions of oncogenic RAS and the p53 tumor suppressor. PLOS Biol 6: $2853-2868$.

Cruickshanks HA, McBryan T, Nelson DM, Vanderkraats ND, Shah PP, van Tuyn J, Singh Rai T, Brock C, Donahue G, Dunican DS, et al. 2013. Senescent cells harbour features of the cancer epigenome. Nat Cell Biol 15: 1495-1506.

d'Adda di Fagagna F, Reaper PM, Clay-Farrace L, Fiegler H, Carr P, Von Zglinicki T, Saretzki G, Carter NP, Jackson SP. 2003. A DNA damage checkpoint response in telomere-initiated senescence. Nature 426: 194-198.

de Melo J, Du G, Fonseca M, Gillespie LA, Turk WJ, Rubenstein JL, Eisenstat DD. 2005. Dlx1 and Dlx2 function is necessary for terminal differentiation and survival of late-born retinal ganglion cells in the developing mouse retina. Development 132: 311-322.

de Melo J, Zhou QP, Zhang Q, Zhang S, Fonseca M, Wigle JT, Eisenstat DD. 2008. Dlx2 homeobox gene transcriptional regulation of Trkb neurotrophin receptor expression during mouse retinal development. Nucleic Acids Res 36: 872-884.

Dimri GP. 1995. A novel biomarker identifies senescent human cells in culture and in aging skin in vivo. Proc Natl Acad Sci 92: 9363-9367.

Eijkelenboom A, Burgering BM. 2013. FOXOs: signalling integrators for homeostasis maintenance. Nat Rev Mol Cell Biol 14: 83-97.

Essers MA, Weijzen S, de Vries-Smits AM, Saarloos I, de Ruiter ND, Bos JL, Burgering BM. 2004. FOXO transcription factor activation by oxidative stress mediated by the small GTPase Ral and JNK. EMBO J 23: 4802-4812.

Gao J, Aksoy BA, Dogrusoz U, Dresdner G, Gross B, Sumer SO, Sun Y, Jacobsen A, Sinha R, Larsson E, et al. 2013. Integrative analysis of complex cancer genomics and clinical profiles using the cBioPortal. Sci Signal 6: pll.

Gordon CT, Brinas IM, Rodda FA, Bendall AJ, Farlie PG. 2010. Role of Dlx genes in craniofacial morphogenesis: Dlx2 influences skeletal patterning by inducing ectomesenchymal aggregation in ovo. Evol Dev 12: 459-473.

Hayflick L, Moorhead PS. 1961. The serial cultivation of human diploid cell strains. Exp Cell Res 25: 585-621.

Herbig U, Jobling WA, Chen BP, Chen DJ, Sedivy J. 2004. Telomere shortening triggers senescence of human cells through a pathway involving ATM, p53, and p21(CIP1), but not p16 (INK4a). Mol Cell 14: 501-513.

Herbig U, Ferreira M, Condel L, Carey D, Sedivy JM. 2006. Cellular senescence in aging primates. Science 311: 1257.
Horejsi Z, Takai H, Adelman CA, Collis SJ, Flynn H, Maslen S, Skehel JM, de Lange T, Boulton SJ. 2010. CK2 phospho-dependent binding of R2TP complex to TEL2 is essential for mTOR and SMG1 stability. Mol Cell 39: 839-850.

Hurov KE, Cotta-Ramusino C, Elledge SJ. 2010. A genetic screen identifies the Triple T complex required for DNA damage signaling and ATM and ATR stability. Genes Dev 24: 1939-1950.

Kenyon CJ. 2010. The genetics of ageing. Nature 464: 504-512.

Krishnamurthy J. 2006. p16INK4a induces an age-dependent decline in islet regenerative potential. Nature 443: 453-457.

Krizhanovsky V. 2008. Senescence of activated stellate cells limits liver fibrosis. Cell 134: 657-667.

Kuilman T. 2008. Oncogene-induced senescence relayed by an interleukin-dependent inflammatory network. Cell 133: 1019-1031.

Kuilman T, Michaloglou C, Vredeveld LC, Douma S, van Doorn R, Desmet CJ, Aarden LA, Mooi WJ, Peeper DS. 2008. Oncogene-induced senescence relayed by an interleukin-dependent inflammatory network. Cell 133: 1019-1031.

Li MZ, Elledge SJ. 2007. Harnessing homologous recombination in vitro to generate recombinant DNA via SLIC. Nat Methods 4: 251-256.

Lu T, Aron L, Zullo J, Pan Y, Kim H, Chen Y, Yang TH, Kim HM, Drake D, Liu XS, et al. 2014. REST and stress resistance in ageing and Alzheimer's disease. Nature 507: 448-454.

Luo J, Emanuele MJ, Li D, Creighton CJ, Schlabach MR, Westbrook TF, Wong KK, Elledge SJ. 2009. A genome-wide RNAi screen identifies multiple synthetic lethal interactions with the Ras oncogene. Cell 137: 835-848.

Meena JK, Cerutti A, Beichler C, Morita Y, Bruhn C, Kumar M, Kraus JM, Speicher MR, Wang ZQ, Kestler HA, et al. 2015. Telomerase abrogates aneuploidy-induced telomere replication stress, senescence and cell depletion. EMBO $I$ 34: 1371-1384.

Meerbrey KL, Hu G, Kessler JD, Roarty K, Li MZ, Fang JE, Herschkowitz JI, Burrows AE, Ciccia A, Sun T, et al. 2011. The pINDUCER lentiviral toolkit for inducible RNA interference in vitro and in vivo. Proc Natl Acad Sci 108: 3665-3670.

Michaloglou C, Vredeveld LC, Soengas MS, Denoyelle C, Kuilman T, van der Horst CM, Majoor DM, Shay JW, Mooi WJ, Peeper DS. 2005. BRAFE600-associated senescence-like cell cycle arrest of human naevi. Nature 436: 720-724.

Munoz-Espin D, Canamero M, Maraver A, Gomez-Lopez G, Contreras J, Murillo-Cuesta S, Rodriguez-Baeza A, VarelaNieto I, Ruberte J, Collado M, et al. 2013. Programmed cell senescence during mammalian embryonic development. Cell 155: 1104-1118.

Negrini S, Prada I, D'Alessandro R, Meldolesi J. 2013. REST: an oncogene or a tumor suppressor? Trends Cell Biol 23: 289-295.

Petryniak MA, Potter GB, Rowitch DH, Rubenstein JL. 2007. Dlx1 and Dlx2 control neuronal versus oligodendroglial cell fate acquisition in the developing forebrain. Neuron 55: 417-433.

Rao F, Cha J, Xu J, Xu R, Vandiver MS, Tyagi R, Tokhunts R, Koldobskiy MA, Fu C, Barrow R, et al. 2014. Inositol pyrophosphates mediate the DNA-PK/ATM-p53 cell death pathway by regulating CK2 phosphorylation of Tti1/Tel2. Mol Cell 54: 119-132.

Rual JF, Hirozane-Kishikawa T, Hao T, Bertin N, Li S, Dricot A, Li N, Rosenberg J, Lamesch P, Vidalain PO, et al. 2004. Human ORFeome version 1.1: a platform for reverse proteomics. $G e$ nome Res 14: 2128-2135.

Sdek P, Ying H, Chang DL, Qiu W, Zheng H, Touitou R, Allday MJ, Xiao ZX. 2005. MDM2 promotes proteasome-dependent 
ubiquitin-independent degradation of retinoblastoma protein. Mol Cell 20: 699-708.

Serrano M, Lin AW, McCurrach ME, Beach D, Lowe SW. 1997. Oncogenic ras provokes premature cell senescence associated with accumulation of p53 and p16 ${ }^{\mathrm{INK} 4 \mathrm{a}}$. Cell 88: 593-602.

Shah PP. 2013. Lamin B1 depletion in senescent cells triggers large-scale changes in gene expression and the chromatin landscape. Genes Dev 27: 1787-1799.

Smogorzewska A, de Lange T. 2002. Different telomere damage signaling pathways in human and mouse cells. EMBO I 21: 4338-4348.

Sousa-Victor P, Gutarra S, Garcia-Prat L, Rodriguez-Ubreva J, Ortet L, Ruiz-Bonilla V, Jardi M, Ballestar E, Gonzalez S, Serrano AL, et al. 2014. Geriatric muscle stem cells switch reversible quiescence into senescence. Nature 506: 316-321.

Storer M, Mas A, Robert-Moreno A, Pecoraro M, Ortells MC, Di Giacomo V, Yosef R, Pilpel N, Krizhanovsky V, Sharpe J, et al. 2013. Senescence is a developmental mechanism that contributes to embryonic growth and patterning. Cell 155: 1119-1130.

Takai H, Wang RC, Takai KK, Yang H, de Lange T. 2007. Tel2 regulates the stability of PI3K-related protein kinases. Cell 131: $1248-1259$.

Tang H, Hilton B, Musich PR, Fang DZ, Zou Y. 2012. Replication factor $\mathrm{Cl}$, the large subunit of replication factor $\mathrm{C}$, is proteolytically truncated in Hutchinson-Gilford progeria syndrome. Aging Cell 11: 363-365.

Tang P, Huang H, Chang J, Zhao GF, Lu ML, Wang Y. 2013. Increased expression of DLX2 correlates with advanced stage of gastric adenocarcinoma. World J Gastroenterol 19: 2697-2703.

Uchida C, Miwa S, Kitagawa K, Hattori T, Isobe T, Otani S, Oda T, Sugimura H, Kamijo T, Ookawa K, et al. 2005. Enhanced
$\mathrm{Mdm} 2$ activity inhibits $\mathrm{pRB}$ function via ubiquitin-dependent degradation. $E M B O$ I 24: 160-169.

van der Horst A, de Vries-Smits AM, Brenkman AB, van Triest $\mathrm{MH}$, van den Broek N, Colland F, Maurice MM, Burgering BM. 2006. FOXO4 transcriptional activity is regulated by monoubiquitination and USP7/HAUSP. Nat Cell Biol 8: 1064-1073.

von Zglinicki T. 2002. Oxidative stress shortens telomeres. Trends Biochem Sci 27: 339-344.

Wu P, Takai H, de Lange T. 2012. Telomeric 3 ' overhangs derive from resection by Exol and Apollo and fill-in by POT1b-associated CST. Cell 150: 39-52.

Yan ZH, Bao ZS, Yan W, Liu YW, Zhang CB, Wang HJ, Feng Y, Wang YZ, Zhang W, You G, et al. 2013. Upregulation of DLX2 confers a poor prognosis in glioblastoma patients by inducing a proliferative phenotype. Curr Mol Med 13: 438-445.

Yilmaz M, Maass D, Tiwari N, Waldmeier L, Schmidt P, Lehembre F, Christofori G. 2011. Transcription factor Dlx2 protects from TGF $\beta$-induced cell-cycle arrest and apoptosis. EMBO I 30: 4489-4499.

Yoon JC, Ling AJ, Isik M, Lee DY, Steinbaugh MJ, Sack LM, Boduch AN, Blackwell TK, Sinclair DA, Elledge SJ. 2014. GLTSCR2/PICT1 links mitochondrial stress and Myc signaling. Proc Nat1 Acad Sci 111: 3781-3786.

Zhang S, Tang Q, Xu F, Xue Y, Zhen Z, Deng Y, Liu M, Chen J, Liu S, Qiu M, et al. 2009. RhoA regulates G1-S progression of gastric cancer cells by modulation of multiple INK4 family tumor suppressors. Mol Cancer Res 7: 570-580.

Zou Q, Jin J, Hu H, Li HS, Romano S, Xiao Y, Nakaya M, Zhou X, Cheng X, Yang P, et al. 2014. USP15 stabilizes MDM2 to mediate cancer-cell survival and inhibit antitumor $\mathrm{T}$ cell responses. Nat Immunol 15: 562-570. 


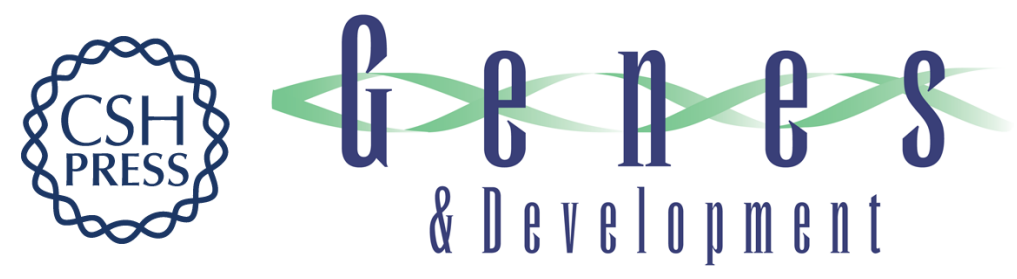

\section{A gain-of-function senescence bypass screen identifies the homeobox transcription factor DLX2 as a regulator of ATM-p53 signaling}

Yifan Wang, Qikai Xu, Laura Sack, et al.

Genes Dev. 2016, 30:

Access the most recent version at doi:10.1101/gad.271445.115

Supplemental http://genesdev.cshlp.org/content/suppl/2016/01/29/30.3.293.DC1
Material

References This article cites 57 articles, 18 of which can be accessed free at: http://genesdev.cshlp.org/content/30/3/293.full.html\#ref-list-1

Creative This article is distributed exclusively by Cold Spring Harbor Laboratory Press for the first Commons six months after the full-issue publication date (see

License http://genesdev.cshlp.org/site/misc/terms.xhtml). After six months, it is available under a Creative Commons License (Attribution-NonCommercial 4.0 International), as described at http://creativecommons.org/licenses/by-nc/4.0/.

Email Alerting Receive free email alerts when new articles cite this article - sign up in the box at the top Service right corner of the article or click here.

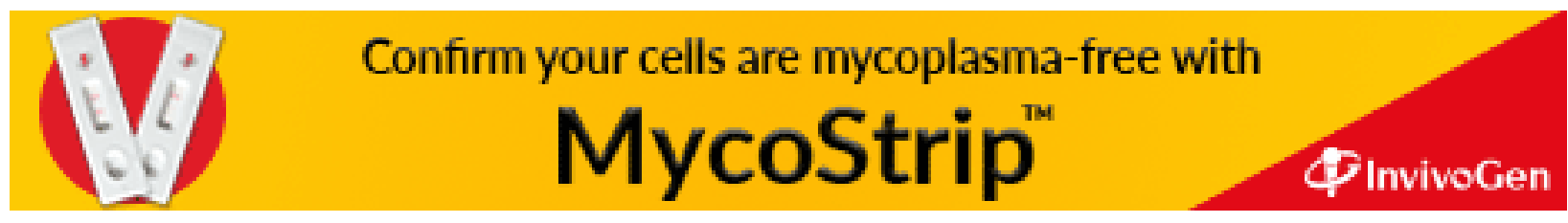

